How open is too open? The mitigating role of appropriation mechanisms in R\&D cooperation settings

Peer-reviewed author version

Veer, Theresa; LORENZ, Annika \& Blind, Knut (2016) How open is too open? The mitigating role of appropriation mechanisms in $R \& D$ cooperation settings. In: $R \& D$ MANAGEMENT, 46(S3), p. 1113-1128.

DOI: $10.1111 / \mathrm{radm} .12232$

Handle: http://hdl.handle.net/1942/22844 


\title{
How open is too open? The mitigating role of appropriation mechanisms in $R \& D$ cooperation settings
}

\begin{abstract}
In this article, we investigate the influence of firms' R\&D cooperation activities on their likelihood to experience imitation. Analyses of firm-level survey data concerning the R\&D cooperation behavior of 2,797 German firms reveal that companies engaging in R\&D cooperation face significantly more imitation than their peers that do not cooperate on R\&D. Further, we show that cooperation with all potential collaboration partner types except universities and research institutions and in all phases of the innovation process increases the risk of imitation. While we find evidence that intellectual property rights (IPR) generally work well as governance mechanisms moderating the relationship between R\&D cooperation and imitation, contracts do not. Hence, IPR apparently provide better protection against imitation than contracts. Our findings indicate that the risks associated with firms' increased engagement in $R \& D$ cooperation could eventually harm the production of new knowledge.
\end{abstract}

Keywords: R\&D cooperation; Imitation; Intellectual Property; Innovation Process; Governance mechanisms 


\section{Introduction}

Continuous innovation requires knowledge and/or input from external partners (Tsai, 2001). Firms increasingly rely on external knowledge outside their boundaries and R\&D collaboration with various stakeholders has vastly increased over the last decades (Tether, 2002). As a consequence, many firms in different industries have transitioned from producerdriven, closed innovation activities to more open and collaborative approaches of managing their innovation and research and development (R\&D) processes (Gassmann et al., 2010). Extant research has repeatedly shown the positive effect of external knowledge and technology sourcing through collaborative efforts on performance and innovative output (e.g., Belderbos et al., 2004; Hagedoorn, 2002). R\&D cooperation, however, also exhibits a "dark side" of negative effects due to appropriability problems, unwanted knowledge leakage, imitation and costs related to these (Foss et al., 2010; Husted and Michailova, 2010; Ritala et al., 2015). Giarratana and Mariani (2014), Buss and Peukert (2015) and Schubert (2015) provide first insights into the relationship between R\&D cooperation/outsourcing and imitation: Giarratana and Mariani (2014) examine the interconnection of external knowledge sourcing and the fear of imitation which may hinder companies from engaging in collaborative R\&D.

While knowledge leakage clearly has a knowledge transfer dimension (Frishammar et al., 2015), the key challenge is to balance the need for an open knowledge exchange regime with the need to control knowledge flows and exchanges to avoid unwanted knowledge leakage (Oxley and Sampson, 2004). As a result, firms use various combinations of governance mechanisms to mitigate these drawbacks and thus to ensure appropriability and value capturing. Not surprisingly, in previous research appropriability is often discussed as enabling successful inter-firm R\&D cooperation (Teece, 1986; Chesbrough, 2003; Hertzfeld et al., 2006; Pisano and Teece, 2007; Henttonnen et al, 2016). Managers use the protective power to 
limit harmful imitation, or to retain some control over knowledge exchange (Breschi et al., 2000; Hurmelinna-Laukkanen, 2009). Appropriability can serve as a signal of a safe knowledge exchange and thereby promote the firm's internal expertise, and subsequently allow for the acquisition of new knowledge in return (Hurmelinna- Laukkanen, 2009). As a result, we differentiate and investigate two types of governance mechanisms found to be particularly relevant to secure appropriability in R\&D cooperation settings: IPR protection registered rights such as patents, trademarks, and copyrights ${ }^{1}$ - and contracts (Somaya et al., 2011; Henttonnen et al., 2016; Schubert, 2015).

In addition to intellectual property protection, contractual governance has been investigated as an important means to further manage the tensions associated with firms' engagement in R\&D partnerships (Dahlander and Gann, 2010; Morasch, 1995; Oxley and Sampson, 2004). First contributions have mainly focused on IPR to structure (international) R\&D partnerships (Oxley, 1997; Oxley, 1999) but the interdependencies between IPR and contracts to efficiently manage R\&D collaborations have been underexplored. To summarize, this paper focuses on governance mechanisms as a mitigating factor against the appropriability hazards and tensions associated with R\&D collaboration, taking into account the potential for imitation, knowledge leakage and opportunism. ${ }^{2}$

At the intersection of rising tensions between collaboration and appropriation, we currently lack a deeper understanding of firms' use of governance mechanisms in collaborations that cover different phases of the innovation process. A vague, non-codified idea emerging from a $R \& D$ partnership requires a different protection method than a

1 Research differentiates between formal and informal IP protection mechanisms. In this study, we focus on formal protection instruments (e.g., patents, registered designs, etc.) to capture value. Formal IP protection measures have shown to be more relevant in R\&D collaboration settings as many informal measures (e.g. secrecy) do not entirely safeguard against information leakage or knowledge spillovers in competitive or high-tech industries (Mansfield, 1985; James et al., 2013; Kultti et al., 2007). Although secrecy can protect an innovation from imitation, it may also entail significant costs and constrain information spillovers that are needed to work efficiently together in an R\&D cooperation setting (Cassiman and Veugelers, 2002).

2 In our sample we possess information on both formal and informal R\&D cooperation settings which allow us to compare the relevance of IPR and contracts as coping mechanisms for both arrangements. 
prototype or physical product developed together with an R\&D partner (Bader, 2008).

Following Utterback $(1971,1974)$, we consider external knowledge sharing at different phases of the innovation process, and thus explore how external partnerships are important at different stages of innovation and how these phases associate with imitation. Additionally, we investigate the role of different governance mechanisms (IPR and contracts) in mitigating the risk of imitation arising from $\mathrm{R} \& \mathrm{D}$ cooperation with different partners (Czarnitzki et al., 2015) and in different phases of the innovation process (Hussinger, 2006). Thus, our main research question investigates how collaboration breadth and scope associate with imitation. The accompanying sub-questions are related to the innovation process which we split up in three different phases from idea generation, problem-solving to commercialization and to the specific R\&D cooperation partner types. We argue that firms' exposure to imitation risk depends on their particular choice of collaboration (which partner types and innovation phase) as well as the nature of the governance mechanisms associated with the collaboration.

Previous studies have mainly investigated the most effective governance mechanism available for a certain type of partner in collaborative $R \& D$, but very few focus on the respective phase of the innovation process in which collaboration takes place (Henttonnen et al., 2016; Manzini and Lazzarotti, 2015). In sum, there is a lack of (quantitative) empirical evidence on how to employ different governance mechanisms in different phases of the entire innovation process and with different types of partners to mitigate the risk of imitation.

We position our study in the ongoing and increasingly active scholarly conversation on R\&D cooperation and appropriability. We intend to make three key contributions to that conversation.

First, while previous studies tend to treat knowledge leakage as a general, aggregated phenomenon (Ritala et al., 2015) that creates issues for firms' value capture and appropriation, we particularly focus on imitation of IP which actually occurred and can thus measure (and be used as an additional indicator for) knowledge spillovers. This is of high 
interest because quantitative evidence on the sensitive topic of knowledge spillovers and imitation in $R \& D$ cooperation is hard to obtain.

Second, we suggest that there is a need for a more thorough understanding of the moderating effects of governance mechanisms (e.g., IPR and contracts) on the relationship between knowledge sharing in R\&D cooperation and imitation. There has been little systematic examination of how appropriability hazards can be mitigated with IPR or contracts in $R \& D$ cooperation (Oxley, 1997). Our results highlight that contracts do not prevent imitation whereas IPR are a better warranty against imitation. Based on this surprising finding, firms can reorganize their external partnership management and couple contracts with other IPR or reconsider their contractual management all over. Different phases in the innovation process require different inputs - from internal and/or external sources as well as different governance mechanisms (Bader, 2008; Hussinger, 2006; Manzini and Lazzarotti, 2015). Additionally, firms may also choose more hierarchical external engagements particularly when governance mechanisms are difficult to specify and when the scope of activities is wider, so that monitoring of activities is hampered (Oxley, 1997).

Third, we further consider and differentiate external knowledge sharing across the innovation process and provide empirical evidence on (1) the effect of imitation in each phase and (2) the relevant governance mechanisms to mitigate that effect. Breaking down the innovation process is relevant to gain a more fine-grained understanding of the respective imitation risk linked to each individual phase and to provide managers with the right toolkit to cope with the risk.

\section{Literature review and hypotheses}

According to the resource-based view (RBV), firms engage in external knowledge sourcing to enhance the likelihood of successful innovation outcomes when they do not possess strong or necessary capabilities in-house (Roper et al., 2008) or the manpower to 
make use of the capabilities. Thus, firms can optimize and benefit from the advantages of both knowledge integration and specialization by engaging in collaboration (Brusoni et al., 2001) in times of increased complexity, accelerated product life cycles and shortened time-to-market (Miotti and Sachwald, 2003). In this paper, we focus on R\&D cooperation since previous scholarly contributions predominantly acknowledge collaboration with external R\&D partners as valuable sources of innovation and value creation (Dyer and Singh, 1998). Additionally, previous research has mainly covered directed knowledge transfer schemes that primarily address situations of conscious, controlled exchanges of knowledge. Despite the various benefits of R\&D cooperation (e.g., achieving a better innovation performance), knowledge may also leak across organizational borders in an uncontrollable and even harmful manner (Giarratana and Mariani, 2014) which can eventually weaken the competitiveness of a firm (Becerra et al., 2008; Easterby-Smith et al., 2008).

\subsection{Hypotheses on knowledge leakage in $R \& D$ cooperation}

A highly relevant topic attended to by innovation scholars deals with the tension between firms' increased tendencies to complement their internal processes with external partnerships while simultaneously focusing on the protection of critical know-how (Bogers, 2011; Laursen and Salter, 2014; Cassiman and Veugelers, 2002). R\&D cooperation has often been described as a double-edged sword: On the one hand firms are able to realize incoming knowledge spillovers to be integrated in their own internal knowledge base; on the other hand firms risk opportunism and loss of commercially valuable (core) know-how to the collaboration partner (Hoecht and Trott, 2006; Hamel, 1991; Frishammar et al., 2015) and thus do not reap the full profits of their in innovation investments (e.g., Ceccagnoli, 2009; Teece, 1986). This is a deeply rooted concern of firm managers highlighting that engaging in external knowledge sharing might come with the cost of risking appropriability (Cassiman and Veugelers, 2002; Alexy et al., 2009; Henkel et al., 2014) acting as a deterrent for firms to enter into 
collaboration settings in the first place (Hamel, 1991; Heiman and Nickerson, 2004; Ritala and Hurmelinna-Laukkanen, 2009) since particularly innovative firms might lose their competitive advantage position without receiving benefits in return (Ritala et al., 2015). Frishammar et al. (2015), however, found that a firm's core know-how may leak to its partners without weakening the firm's competitive situation, while leakage of other, non-core knowledge may have serious negative consequences for the focal firm's competitive position - depending on the specific knowledge base of the respective partner, especially the one of competitors (Hurmelinna-Laukkanen and Olander, 2014). Nonetheless, knowledge leakage that is unconscious, uncontrolled and beneficial to only one party facilitates imitation of a firm's technology, products or services. We define imitation as the unauthorized usage of products or business models of companies, including technology, brands and designs. Thus, imitation represents a "dark side" encompassing various negative consequences for affected firms, including loss of revenue, damaged reputation, decreased bargaining power, loss of productivity and costs (Ahmad et al., 2014).

When firms cooperate in $\mathrm{R} \& \mathrm{D}$, they not only rely on close and obvious partners, such as suppliers and customers, but engage in partnerships with universities, research centers, governmental institutions and even competitors (Laursen and Salter, 2006). Different partner types entail their own peculiarities, mind-sets, routines and (dis)advantages.

We first take a look at the breadth of $R \& D$ cooperation by considering different types of collaboration partners (i.e., competitors, B2B customers, suppliers and universities). This is consistent with current and previous research which defines breadth of collaboration as the number of external partners a firm has (Laursen and Salter, 2006). ${ }^{3}$ We further define scope of $R \& D$ cooperation as the extent to which firms cooperate in different phases along the

3 Cooperation with competitors is less common since the risk of involuntary outward spillover is particularly salient as compared to any other actor in the firm's portfolio of innovation collaboration. Thus, only firms with a strong appropriability strategy will engage in collaborations with competitors (Laursen and Salter, 2014). 
innovation process. This is consistent with the magnitude to which the acquired knowledge is used in different settings to fully leverage it (Katila and Ahuja, 2002).

First, the least risky form of cooperation is to join forces with only one partner for innovation. Here, knowledge flows can be monitored and potential risks of imitation mitigated. Further, a firm may simultaneously cooperate with more than one partner increasing coordination and transaction costs. In this broader approach of cooperation, the firm tries to obtain complementary know-how from different partners simultaneously. Attention-based theory (Ocasio, 1997) suggests that these firms may also find it problematic to focus their efforts equally among all partners (Grimpe and Kaiser, 2010; Laursen and Salter, 2006). Not being able to focus eventually leads to longer feedback loops, slower processes and results. Hence, the more external partners a firm has, the harder it becomes to simultaneously control knowledge exchanges with each individual partner, which further increases the risks of imitation.

Hypothesis 1a: R\&D cooperation breadth is positively associated with imitation of IP. A firm may cooperate with only one partner across different phases of the innovation process. In this very intense form of cooperation, the risk is more controllable. However, as the two firms deeply engage in knowledge exchanges across different phases of the innovation process, there may be the risk of not only exchanging codified knowledge, but also valuable tacit knowledge, core competencies or critical technological capabilities, which can enhance the risk of imitation drastically (Anton and Yao, 2004; Berger et al., 2012). Consequently, being able to control this network of interfirm exchanges is complex (Hoecht and Trott, 2006) and any outgoing knowledge flow difficult to prevent. A company shares knowledge more intensely across the innovation process if it cooperates in many different phases, i.e., if the scope of $R \& D$ cooperation is high. As a result, critical knowledge is shared more deeply and imitation is very likely. Hence, we propose:

Hypothesis 1b: R\&D cooperation scope is positively associated with imitation of IP. 


\subsection{Hypotheses on appropriability in $R \& D$ cooperation}

Firms working with a large number of external partners need to manage these different sources as well as the knowledge resulting from jointly created innovations. As a result, firms employ various governance mechanisms, such as intellectual property rights (IPR) or formal contractual mechanisms, to protect their innovation-based competitive advantages (Czarnitzki et al., 2015; Hurmelinna-Laukkanen and Puumalainen, 2007; Teece, 1986). The literature distinguishes between legal IPR (patents, utility models, design registration, trademarks, copyright) and contractual mechanisms (employee agreements, NDAs, confidentiality agreements) (Cassiman and Veugelers, 2002; Faria and Sofka, 2010; Gallié and Legros, 2012; Laursen and Salter, 2014) to govern R\&D cooperation.

A strong overall governance regime is likely to increase control and the opportunities to gain benefits from various types of R\&D collaboration, and subsequently, a firm with strong mechanisms is more likely to engage in such relationships (Henttonnen et al., 2016).

Next, we hypothesize on the mitigating role of governance mechanisms in this process. Both IPR and contracts provide legal rights that can be used in case of litigation, infringement and counterfeit. Their effectiveness as governance mechanisms depends on their respective capability to secure the appropriation of benefits obtained from the innovation protected (Teece, 1986; Hertzfeld et al., 2006). Contracts are found to be relevant for any type of collaboration partner whereas IPR are also relevant for any partner type except for competitors (Henttonnen et al., 2016) as they disclose too much information. Overall, the strength of firms' governance mechanisms varies according to the type and amount of R\&D collaboration (Henttonnen et al., 2016). Furthermore, contracts set the standard operating routines for the knowledge exchange and can govern the treatment of the collaboration outcomes as well as arising knowledge and IP ownership issues before starting negotiations (Somaya et al., 2011; Gassmann and Bader, 2006). Contractual agreements also govern the 
end of collaboration and the phase of beginning or intensifying competition (Henttonnen et al., 2016). Since clear-cut contracts have a legal character, they can be enforced in court. R\&D cooperation mainly involves highly uncertain activities, such as joint technological innovation and outcomes, which cannot be fully specified in a contract, or adequately monitored and enforced (Oxley, 1997). As a consequence, contracts governing R\&D collaboration are inherently incomplete, causing so-called 'contractual hazards' because the opportunity of moral hazard arises on either side of the transaction. Hence, contracts are only a suboptimal means to prevent knowledge-spillovers. In fact, contracts between the collaboration partners are only found to better prevent imitation in vertical collaboration (Schubert, 2015).

IPR, on the other hand, provide security and reconcile some uncertainty arising from knowledge exchanges in $R \& D$ cooperation encouraging firms to communicate their intangible resources and to safely exchange knowledge, thereby improving the chances of producing valuable innovations (Gans and Stern, 2003). They can serve as a signal that both partners are willing to engage in mutual knowledge exchange without expropriation or imitation which facilitates early initiations of cooperation (Manzini and Lazzarotti, 2015; Henttonnen et al., 2016). Nonetheless, Schubert (2015) observes that patents insufficiently protect technical inventions, which may result in imitation.

Based on the aforementioned arguments, we propose:

Hypothesis 2a: R\&D cooperation breadth will increase the likelihood of imitation more for firms not using IPR than for firms using IPR.

Hypothesis 2b: R\&D cooperation scope will increase the likelihood of imitation more for firms not using IPR than for firms using IPR.

Hypothesis 3a: R\&D cooperation breadth will increase the likelihood of imitation more for firms not using contracts than for firms using contracts. 
Hypothesis 3b: R\&D cooperation scope will increase the likelihood of imitation more for firms not using contracts than for firms using contracts.

\subsection{Prior literature on the innovation process and imitation}

An innovation process comprises a pre-defined linear sequence of phases (Salerno et al., 2015) from idea generation to problem-solving to commercialization. ${ }^{4}$ As described previously, the involvement of partners along the innovation process makes the management and protection of knowledge more difficult (with respect to closed modes of innovation) (Manzini and Lazzarotti, 2015). Moreover, Manzini and Lazzarotti (2015) suggest that in different phases - depending on the intensity of the collaboration at this stage - different aspects of knowledge can spill over. Of course, knowledge exchanged is completely different in the idea generation phase than the end of the innovation process where a final prototype/product needs to be commercialized. Uncertainty seems to play a role, but the loss of critical knowledge in each respective phase can potentially increase the risk of imitation.

During the idea generation phase, a firm mainly cooperates to obtain inspiration for new technological opportunities (Laursen and Salter, 2006; Love et al., 2011). This stage can also entail the definition of the new product concept with the functionality and product specification criteria (Manzini and Lazzarotti, 2015). Furthermore, these early negotiations comprise the exchange of information about the market, the specific technical needs and resources or capabilities that each firm requires (Slowinski et al., 2006). Hence, the companies mainly reveal their sensitive tacit know-how or very early-stage ideas for a new R\&D project. Particularly problematic in this phase is if ideas are being juggled around and there is no non-disclosure agreement in place, which can be a potential source of imitation.

4 Saren (1984) provides a review of different descriptive innovation process models. We conceptualize the stages according to Utterback $(1971,1974)$. 
Contrasting, in the problem-solving phase of the innovation process, R\&D investments are made, $R \& D$ is conducted, the close-to-optimal design of the innovation is developed and critical design components are shared within that phase. The rationale for cooperation at this stage of the innovation process is mainly to realize economies of scale and scope as well as to reduce time and costs associated with extensive R\&D processes (Hagedoorn, 1993). For a fruitful and productive exchange in this phase, a firm may disclose especially critical technological capabilities to its R\&D cooperation partner(s). This leaked technological knowhow can be used by an opportunistic collaboration partner as the basis for imitation.

During the implementation phase, the firm focuses its partnership(s) on exploitative learning, commercializing new products and processes developed earlier (Love et al., 2011). At this stage the companies also exchange complex IP and internal technological knowledge for an optimal production process of the innovation ensuring a successful cooperation outcome. Additionally, during the commercialization stage, a firm may reduce the go-tomarket risk by joining forces with partners possessing access to distribution channels and/or strong manufacturing capacity (Teece, 1986).

As a result, imitation in the different phases heavily depends on the properties of the know-how exchanged and the governance mechanisms employed. Cooperating in R\&D in different stages increases complexity of managing the different ties and the phases of the innovation value simultaneously. Moreover, Hussinger (2006) argues that at different stages of the innovation process - in coherence with the changing level and nature of uncertainty different IPR protection tools may be used (Trott, 2008) which suggests that using IPR prevents imitation. Nonetheless, confidentiality and non-disclosure agreements are usually applied to guarantee knowledge protection in the idea generation phase of joint R\&D. Thus, the more a firm cooperates in different phases of the innovation process, the more it will have governance (IPR/contracts) in place to prevent imitation. 
Additionally, the innovation process is often vague, not clearly organized and different for each individual firm which is reflected - despite some initial seminal works - in a line of research that is still underexplored. Therefore, it is difficult to predict which governance mechanism mitigates imitation according to the phase of the innovation process which is, perhaps, also the result of the confusing array of potential combinations of governance instruments available (Oxley, 1997).

We refrain from formulating explicit hypotheses covering distinct mechanisms related to the innovation process or making strong expectations on causality, especially given that the research in this area is still quite scattered. Instead, we report explorative empirical data on the relationships between imitation and the governance at various stages of the innovation process.

\section{Method}

\subsection{Sample}

For this paper, we use the German Community Innovation Survey (CIS), which is sent out every year to a random sample (stratified by size, region, and sector) of German companies. Among scholars (e.g., Belderbos et al., 2004; Cassiman and Veugelers, 2002; Leiponen and Helfat, 2011; Miotti and Sachwald, 2003; Tether, 2002), the interest in CIS data has risen for two reasons. First, the data provide indicators for innovation performance, and second, CIS data are used as a supplement to traditionally used patent data (Kaiser, 2002; Leiponen and Helfat, 2011). Thus, the downsides of patent data can be tackled. We analyze firm-level data from the CIS 2008, containing information about imitation and about R\&D collaboration with different partners along the three phases of the innovation process. Furthermore, we match European Patent Office patent and trademark stock data, and patent citation data on a 1:1 basis using an ID variable unique to each company throughout the dataset. The final sample set contains 2,797 observations and is cross-sectional. 


\subsection{Measures}

The dependent, binary variable in our analyses is 'Imitation', operationalized based on the question 'Has IP of your company been negatively affected by other companies in the years 2005-2007?'. ${ }^{5}$ Hence the variable codes 1 for imitation and 0 for no imitation.

The explanatory variables all derive from the questionnaire item focusing on $R \& D$ collaboration in the period of 2005-2007. We connect R\&D cooperation activities with imitation in the same period as we suggest that imitation is induced by R\&D cooperation and, hence, the imitation incidence either happens within the collaboration or closely after. The categorical variables focused upon are 'Breadth' and 'Scope' measured by how many different partners a company collaborates (breadth) and in how many different phases (scope). Breadth codes from 0 for collaboration with no partners (i.e., a company without cooperation activities) to 4 representing collaboration with all four possible partner types (i.e., competitors, customers, suppliers, universities/R\&D institutes). Scope ranges from 0 if the company does not collaborate in any phase to 3 coding cooperation within all phases (i.e., idea generation, problem solving and implementation) $)^{6}$. Further variables capture the collaboration activities regarding the different innovation phases and the different collaboration partners, all binary (e.g., if a company collaborates with its supplier, the variable Supplier is coded as 1).

A further set of important variables are the usage of IPR and contracts. Both variables are binary and we use them to split the samples into companies using IPR (contracts) and companies not using IPR (contracts) to govern their innovation collaborations so as to investigate the potential of both to reduce imitation potential. For robustness checks, we

5 Original question in German: "Ist intellektuelles Eigentum Ihres Unternehmens in den Jahren 2005-2007 durch andere Unternehmen beeinträchtigt worden?" Hence, we do not have any information whether this form of imitation is 'real' or just perceived by the firm informant.

6 We decided to simplify the original questionnaire item in accordance with the literature on R\&D collaboration (cf. literature section) and merged the phases R\&D and design into "problem solving" and testing and market introduction into "implementation". 
coded the contract usage variable only as 1 if the company always governs their collaboration with contracts. This change in coding does not affect our results.

In our estimations, we control for variables which scholars have found to influence the likelihood of imitation. Hence, we include the size of the company (Employees $(\ln ))($ Berger et al., 2012; Giarratana and Mariani, 2014; Schubert, 2015), the intensity of exports (Export Intensity (\%)) (Berger et al., 2012; Harhoff and Reitzig, 2004) and of R\&D (R\&D Intensity (\%)) (Berger et al., 2012; Giarratana and Mariani, 2014) both measured as a ratio of sales. Furthermore, we control for sectorial differences using the European NACE code classification, for the influence of patent and trademark stocks [Patent Stock (ln); Trademark Stock (ln)] (Kleinknecht and Reijnen, 1992), and for the influence of IP value by including patent forward citations (citations/patent). As firms' legal capability can influence the ability to draw high quality contracts, file for IPR and spot imitation, we include an indicator for firms' legal capability to exclude this as a potential source of endogeneity. For an overview of all employed variables, please see TABLE 1.

Insert TABLE 1 about here

\subsection{Statistical method}

We cannot directly investigate whether the company faced infringement within an $R \& D$ collaboration. However, we argue that the decision to collaborate in the innovation process is a conscious, long-term decision that emphasizes a firm's engagement in cooperation on a general scale. Hence, we do not claim that a specific cooperation with a specific partner is causing a specific imitation incidence. We used logistic regression analysis computing oddsratios as the dependent variable is binary. As the estimated regressions roughly lack $35 \%$ of observations contained in the data set, we also conducted a non-response analysis (t-tests) to 
make sure that companies that did not give particulars about their imitation experience or open innovation behavior significantly differ from the ones that did. The t-tests do not reveal any significant differences and are available upon request. In line with recommendations to treat missing data, the observations with missing values in one or more variables are listwise deleted from the estimations (Allison, 2002).

\section{Results}

The descriptive statistics in FIGURES 1-3 reveal some interesting results. Imitation is connected to all phases of the innovation process; around 30\% of all firms engaging in the different phases face imitation. When we split the firms up by the partner type they collaborate with, the descriptive statistics reveal that the range of imitated firms is from $36 \%$ firms collaborating with universities or research institutions facing imitation to $28 \%$ of firms cooperating with suppliers. In short, around one third of all collaborating firms face imitation. Firms using IPR or contracts to govern collaborations seem to be more affected by imitation, however, we have to control for confounding factors, e.g., IP value, IP stock, firm size, etc. Hence, only the regression analyses reveal significant relationships between the variables.

Our results show that collaboration breadth and scope are both positively associated with imitation. Each additional partner increases the likelihood of imitation by $47 \%$ and each additional phase of cooperation by $33 \%$ (TABLE 2 ). Hence, both hypotheses $1 \mathrm{a}$ and $1 \mathrm{~b}$ are supported by our estimations. Furthermore, our models support evidence with regard to hypotheses $2 \mathrm{a}$ and $2 \mathrm{~b}$ but not for hypotheses $3 \mathrm{a}$ and $3 \mathrm{~b}$.

Insert TABLE 1 about here 
We find a mitigating effect of IPR while we fail to find a mitigating role of contracts. Apparently, firms with a high collaboration breadth or scope do not exhibit a higher likelihood for imitation if they use IPR. The significant Wald test of the split sample models 5 and 6 reveals that the differences between both models are indeed caused by the use (or nonuse) of IPR and that these differences are significant at the 5\% level. Contrasting, the differences between model 7 and 8 fail the Wald test. Hence, we cannot interpret the differences between the models as caused by the (non-) use of contracts.

Further, our results show that collaboration within the problem solving phase is most highly associated with imitation (160\% more likely), while collaboration in the idea generation and imitation phase cause significant imitation but to a lesser extent $(68 \%$ and $40 \%$ more likely, respectively). Analyzing the mitigating effect of IPR for different phases along the innovation process, we find that IPR do mitigate the effect in the problem solving phase but not in the idea generation phase in which they seem to have a rather enabling effect. We find no differences for the implementation phase. All these differences are significant at the $5 \%$ level as indicated by the Wald test. In regard to contracts' mitigating effect, we do find differences, but these cannot be attributed to the (non-) use of contracts as the Wald test is not significant.

Additionally, we find that all types of partners are positively associated with imitation with the exception of universities and research institutions. B2B customers exhibit the highest odds-ratio suggesting that firms cooperating with the B2B customers face a $155 \%$ increased likelihood of imitation. Collaborating with suppliers increases imitation likelihood by $90 \%$ and with competitors by $36 \%$. With respect to IPR usage our findings show companies collaborating with suppliers or competitors do not face an increased risk of imitation if they employ IPR while using IPR does not mitigate the higher imitation risk stemming from collaboration with B2B customers. As the Wald test is significant at the 5\% level, we can 
attribute these differences indeed to the (non-) use of IPR. As with regard to the use of contracts our models fail the Wald test. Hence, the use of contracts does not influence the likelihood of collaborating companies being imitated.

With respect to the use of IPR, we differentiate further between various types of IPR to disentangle and further nuance our models according to patent, design and trademark use for the different phases along the innovation process and for the different partner types, respectively. The Wald tests of the model differences reveal a significant influence of all IPR with respect to the different collaboration phases. For collaboration in the idea phase, we find that the non-use of patents is associated with no significant increase in imitation and the use of patents is associated with imitation. This suggests that patents have an imitation enabling effect in the ideation phase rather than impeding imitation. The opposite is true for the problem solving and implementation phase. Firms collaborating in these phases do not face an increase in imitation if they employ patents. Hence, patents are a good means to control the higher imitation risk in all phases with the exception of the ideation phase. Contrastingly, the use of design mitigates the increased risk of imitation induced by collaboration in any phase. Trademarks are especially effective to dampen imitation in the problem solving phase.

Analyzing differences for the mitigating effect of IPR for different partner types, our results reveal an interesting picture. With respect to collaboration with $\mathrm{B} 2 \mathrm{~B}$ customers, no IPR type mitigates the increased imitation risk. Neither the use of patents, nor designs, or trademarks make a difference in the increased imitation risk induced by cooperation with B2B customers.

\section{Discussion}

Our paper shows that R\&D collaborations are associated with an increased risk of firms being imitated. As firms are interested in both collaborating and safeguarding against imitation, the effectiveness of governance mechanisms is of utmost interest. Our results 
emphasize that IPR generally mitigate the imitation risk induced by R\&D collaboration quite well. This is in line with our theoretical argumentation and confirms our expectations adding to previous research in the field (Laursen and Salter, 2014). However, contracts as a widespread mechanism to govern R\&D collaboration do not have a mitigating effect on imitation. For firms engaging in $R \& D$ cooperation it makes no difference to employ contracts or to cooperate without a contractual basis with regard to the induced imitation risk. This is a very striking finding which brings the effectiveness of contracts for $R \& D$ cooperation with respect to involuntary spillover into question. It is indeed startling that contracts — despite their wide application - do not deliver on their promise to protect firms from imitation resulting from R\&D cooperation. Although both IPR and contracts represent legal instruments that can be enforced in court, our results highlight that contracts are not as powerful as IPR when it comes to protection from imitation. We interpret our findings such that R\&D collaborations are complex forms of inter-firm exchanges in which contracts by nature will be incomplete as it is very difficult to predict the outcome of such collaborations (Oxley, 1997). Detailed legal contracts mainly protect tangible outcomes from specific collaboration projects, but not every innovation related project outcome is tangible and therefore not necessarily clearly defined in legal contracts (Hoecht and Trott, 2006). Contrasting, IPR, such as patents, are quite specific legal documents which link the imitated technology to an exact patent or group of patents. Contracts usually are more general in nature and often feature standard clauses of potential knowledge leakage and cooperation behavior between the partners. As with joint R\&D, cooperation technology is collaboratively developed, a flow of knowledge into the technology exists and the final product is mainly tacit in nature and difficult to specify, which hampers the enforcement of contracts. In terms of knowledge leakage and imitation, the copied technology and knowledge cannot exactly be traced back to the contract as they do not contain any product specifications. 
Notwithstanding, our results also highlight that IPR are not always a magic bullet. Particularly patents are known for their imitation enabling effect (Anton and Yao, 2004; Berger et al., 2012) as they contain valuable technical information on how to successfully execute an invention. However, without complementary tacit knowledge, the usage of this disclosed knowledge is often difficult, if not impossible, for parties lacking this tacit knowledge (Cohen and Levinthal, 1990; Henttonnen et al., 2016; Hurmelinna-Laukkanen and Olander, 2014). Our results suggest that the enabling effect of patents is prone to trigger imitation especially if tacit knowledge is exchanged in the idea generation phase that is further accompanied by patents, opportunistic firms may take advantage of that situation and appropriate the know-how for further own developments without engaging in subsequent stages of joint R\&D cooperation. Still, patent protection in later stages works well as a governance mechanism.

Further, patents do not provide protection from imitation induced by cooperation with B2B customers. Collaboration with B2B customers induces a high risk of imitation as the production lines and processes can easily be integrated due to the relative closeness of the supplier's IP and, consequently, the high absorptive capacity of the B2B customer (Cohen and Levinthal, 1990; Hurmelinna-Laukkanen and Olander, 2014). Our results suggest that firms shy away from enforcing their infringed IPR against their own customers as they have to outweigh the benefits of enforcement (e.g., potential royalties, lower competition due to injunctions) against the major drawback of losing a customer. As this dilemma is probably anticipated by the customers they feel relatively safe in using their suppliers' IP.

\section{Conclusion and implications}

A joint engagement in an $R \& D$ project may represent the beginning of a process of value creation (Roper et al., 2008). This paper highlights the imitation risk firms' face when collaborating on R\&D and analyzes this risk for different partner types and for the different 
phases along the innovation process. By differentiating between collaboration breadth, our results demonstrate that each additional phase and partner type increase the risk of imitation. Splitting our models according to the partner types and phases, we show that especially the problem solving phase is prone to cause imitation and the partner type most highly associated with imitation is $\mathrm{B} 2 \mathrm{~B}$ customers while universities and research institutions are no-risk partners in this sense. Concluding, our theoretical predictions for these base models hold, which suggests that imitation is closely linked to the firm's level of external engagement and hereby confirm previous research (Laursen and Salter, 2014; Bogers, 2011; Cassiman and Veugelers, 2002). In sum, this study shows that there is a tradeoff between risk hedging (a lot of partners and phases enable a lot of different innovations and increase the probability of at least one successful innovation) and risk inducing effects (breadth and scope relate to imitation).

\subsection{Theoretical implications}

Our findings highlight that firms especially have to safeguard from imitation induced by cooperation with B2B customers. We further suggest that IPR, such as patents, trademarks and registered designs, mitigate the imitation risk induced by R\&D cooperation. Firms cooperating on R\&D do not face significantly more imitation than their non-cooperative peers if they employ IPR to protect their critical know-how with the exception of collaboration with $\mathrm{B} 2 \mathrm{~B}$ customers and the usage of patents in the idea generation phase. Most strikingly, we show that contracts do not mitigate the imitation risk as induced by R\&D collaboration despite their widespread use. Our findings have implications for contract theory (Mayer and Salomon, 2006; Poppo and Zenger, 2002; Oxley, 1997; Oxley, 1999; Oxley and Sampson, 2004) by providing nuanced information for its limitations in R\&D cooperation settings. Moreover, given that IPR legislation is also not exhaustive, the firm should be able to draft 
contractual arrangements to support the establishment of common norms and trust (Henttonnen et al., 2016).

\subsection{Managerial implications}

Our results have important implications for innovation and R\&D managers who wish to enter collaboration and to safeguard from imitation. Collaborating with B2B customers induces a very high imitation risk which is difficult to mitigate by both contracts and IPR. Hence, firms collaborating with their B2B customers need to find alternative ways to appropriate the rents from their IP and establish a trusting relationship with their customers with whom they collaborate. For firms collaborating during the idea generation phase, patents are imitation enabling rather than mitigating. These results indicate that patent intensive firms need to find different ways to protect their IP from imitation when entering collaborations in the idea generation phase. Design and trademark protection offer a superior alternative to patents for the idea generation phase as suggested by our estimations. We suggest that in the context of R\&D cooperation the enabling effect of patents is of particular importance at the ideation phase while being less relevant in later stages of collaboration. Hence, managers need to be aware of how to use which IPR for each collaboration phase. A holistic management of IPR supported by contracts before, during and after an R\&D collaboration is key to protect from imitation. Without a sufficiently governed IP ownership before entering the collaboration contracts the partners are not able to specify a distinct IP ownership setting, i.e., distinguishing ex ante the status quo of IP ownership. This can be achieved when firms rely on a "selective revealing" strategy that involves only partial disclosure of some essential aspects of the exchanged knowledge while controlling access to strategically important aspects of the knowledge (Laursen and Salter, 2014; Henkel et al., 2014; Alexy et al., 2013). Consequently, a firm's awareness of its core competencies and capabilities and which of these are critical for its performance and competitive advantage is the prerequisite for appropriate 
governance protection decisions. Nonetheless, crafting contracts with cooperation partners, firms must consider not only overlapping core knowledge, but also overlapping non-core knowledge competitors could profit from (Frishammar et al., 2015). Hence, firms choose a suitable partner and an innovation phase in which they can offer less critical resources and capabilities that are still valuable for the partner. As a result, we expect firms to analyze the innovation process with regard to the most beneficial phase and partner to cooperate in and with and, hence, to optimize their R\&D cooperation strategy, accordingly.

\subsection{Limitations and further research}

While our study provides important contributions and shows that contracts can only complement other existing IPR to mitigate the spillover risk inherent to R\&D collaboration settings, some questions remain unanswered providing exciting opportunities for further research. Our findings highlight that the employment of IPR works much better in mitigating the imitation risk induced by $R \& D$ collaboration; however, we are not able to estimate an interaction effect between contract and IPR use. This could provide an interesting opportunity for future research endeavors. We further suggest that both governance mechanisms potentially complement each other and that contracts can enhance the protection provided by IPR. Another problem that arises is the capacity of managers to maintain and control all their R\&D partners at the same time. It might be more difficult to handle two partners of different types (e.g., a university and a competitor) than more than two partners of one type (e.g., three competitors). Therefore, it is interesting to shed light on and thus add to R\&D cooperation literature by examining whether the (coordination, transaction cost) effort increases when a firm cooperates e.g., with two instead of only one B2B customer and compare it to the effort of one handling one B2B customer and adding a university as a cooperation partner. Thus, future research could investigate firms' portfolio play regarding the different kinds of organizations as $R \& D$ cooperation partners. We demonstrate that all $R \& D$ cooperation 
partner types except research institutions influence firms' likelihood to experience imitation. For some affected firms this could serve as a signal to improve their current appropriation capability. However, our findings do not differentiate the degree and severity of the imitation experience. It would be interesting and highly rewarding for theory building concerning the creation of firms' appropriation capability to investigate the nature of imitation incidences and whether they arose from a particular R\&D partnership. In line with Frishammar et al. (2015) we suggest to further build on our findings by specifically differentiating between core/noncore technologies and their impact on firm's imitation experience as well as their competitive position. Additionally, the empirical evidence presented in this article should be considered carefully and influenced by the indicators of R\&D cooperation and imitation adopted by CIS (Evangelista and Vezzani, 2010). The data collected in innovation surveys are qualitative, subjective, censored and cross-sectional in nature which does not allow for strong causal claims (Mairesse and Mohnen, 2010). In this vein, we lack project-level information and hope that future research can look in more detail into those dyadic relationships at a project-level. Additionally, our study focuses on a single country over a single time period. As a consequence, the possible time lag effect between the arrangement of formal cooperation and imitation cannot be investigated. Another limitation of this study lies in the fact that the survey is subjective and based on assertions of individual firms on their actual collaboration behavior and imitation experience. Although reliability and validity of the survey have been established, some questions may remain slightly subjective and rely on the perception of the respondent and his/her involvement in innovation activities. 


\section{Appendix}

FIGURE 1: Frequency of imitation across the innovation process

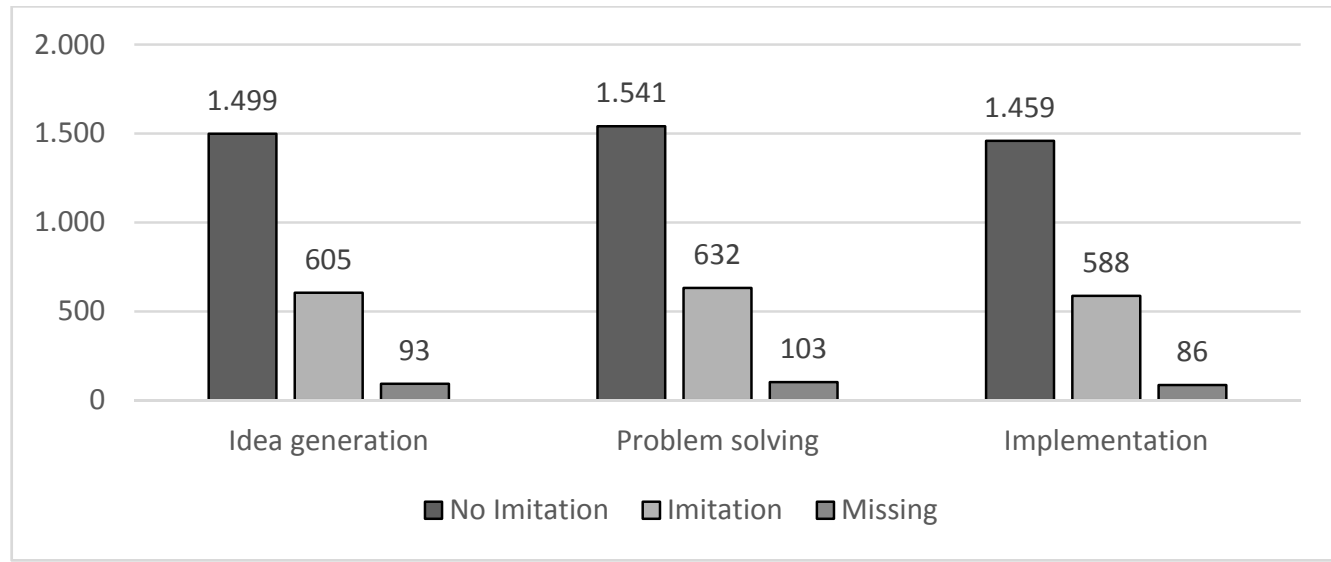

FIGURE 2: Frequency of imitation for different partner types

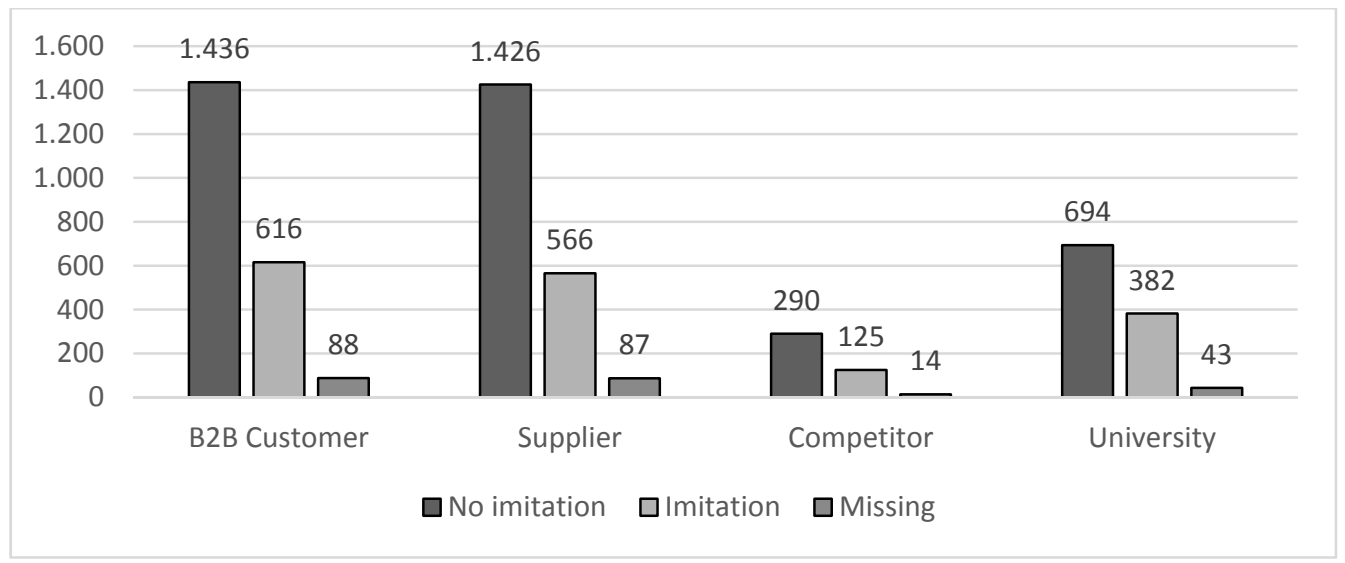

FIGURE 3: Frequency of firms engaged in $R \& D$ cooperation using IPR and/or

\section{contracts}

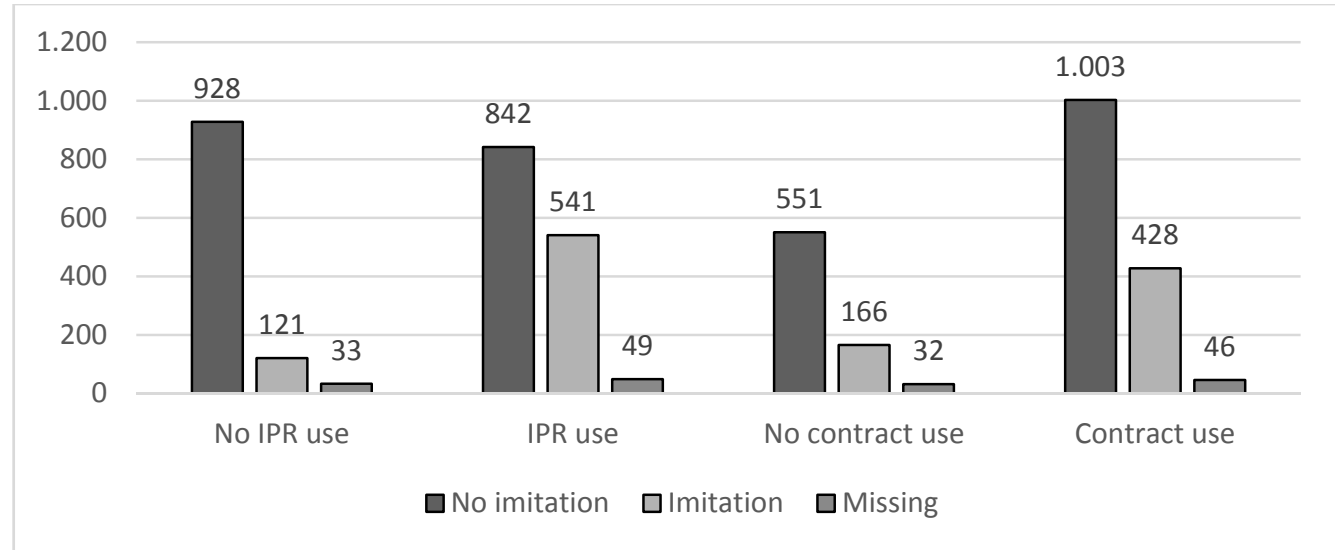

TABLE 1: Overview of variables 


\begin{tabular}{llllll} 
Imitation & 2797 & 0.20 & 0.40 & 0 & 1 \\
\hline Scope of open innovation (\# of different stages 0-3) & 2797 & 1.73 & 1.31 & 0 & 3 \\
Breadth of open innovation (\# of different partner types 0-4) & 2797 & 1.49 & 1.25 & 0 & 4 \\
Idea generation & 2797 & 0.57 & 0.49 & 0 & 1 \\
Problem solving & 2797 & 0.59 & 0.49 & 0 & 1 \\
Implementation & 2797 & 0.56 & 0.50 & 0 & 1 \\
B2B Customer & 2797 & 0.54 & 0.50 & 0 & 1 \\
Supplier & 2797 & 0.54 & 0.50 & 0 & 1 \\
Competitor & 2797 & 0.11 & 0.31 & 0 & 1 \\
University & 2797 & 0.30 & 0.46 & 0 & 1 \\
\hline IPR use & 2715 & 0.44 & 0.50 & 0 & 1 \\
Contract use & 1833 & 0.64 & 0.48 & 0 & 1 \\
Patent use & 2647 & 0.34 & 0.47 & 0 & 1 \\
Design use & 2408 & 0.08 & 0.27 & 0 & 1 \\
Trademark use & 2562 & 0.30 & 0.46 & 0 & 1 \\
\hline Employees (ln) & 2797 & 3.90 & 1.72 & 0 & 12.16 \\
R\&D intensity (\%) & 2797 & 0.02 & 0.09 & 0 & 1.34 \\
Exports intensity (\%) & 2797 & 0.17 & 0.25 & 0 & 1 \\
Patent stock (ln) & 2797 & 0.24 & 0.64 & 0 & 5.64 \\
Trademark stock (ln) & 2797 & 0.11 & 0.41 & 0 & 4.98 \\
IP value (citations/patent) & 2797 & 0.22 & 1.28 & 0 & 39.20 \\
Legal experience & 2797 & 0.03 & 1.02 & -0.32 & 3.90 \\
Pharmaceutical & 2797 & 0.01 & 0.12 & 0 & 1 \\
Computer, electronics, optical products & 2797 & 0.05 & 0.23 & 0 & 1 \\
Chemicals & 2797 & 0.03 & 0.16 & 0 & 1 \\
Electrical equipment & 2797 & 0.03 & 0.18 & 0 & 1 \\
Machinery incl. installation & 2797 & 0.08 & 0.27 & 0 & 1 \\
Automotive & 2797 & 0.03 & 0.16 & 0 & 1 \\
Rubber, plastic, and other non-metal & 2797 & 0.07 & 0.25 & 0 & 1 \\
Metal production & 2797 & 0.08 & 0.28 & 0 & 1 \\
Food, beverage, tobacco & 2797 & 0.04 & 0.19 & 0 & 1 \\
Apparel & 2797 & 0.03 & 0.18 & 0 & 1 \\
Lumber, pulp, paper & 2797 & 0.03 & 0.17 & 0 & 1 \\
Print & 2797 & 0.02 & 0.13 & 0 & 1 \\
Other manufacturing & 2797 & 0.04 & 0.19 & 0 & 1 \\
Knowledge-intensive services & 2797 & 0.21 & 0.41 & 0 & 1 \\
Less knowledge-intensive service (Reference category) & 2797 & 0.14 & 0.35 & 0 & 1
\end{tabular}

TABLE 2: Base model: Logistic regression - breadth and scope of innovation

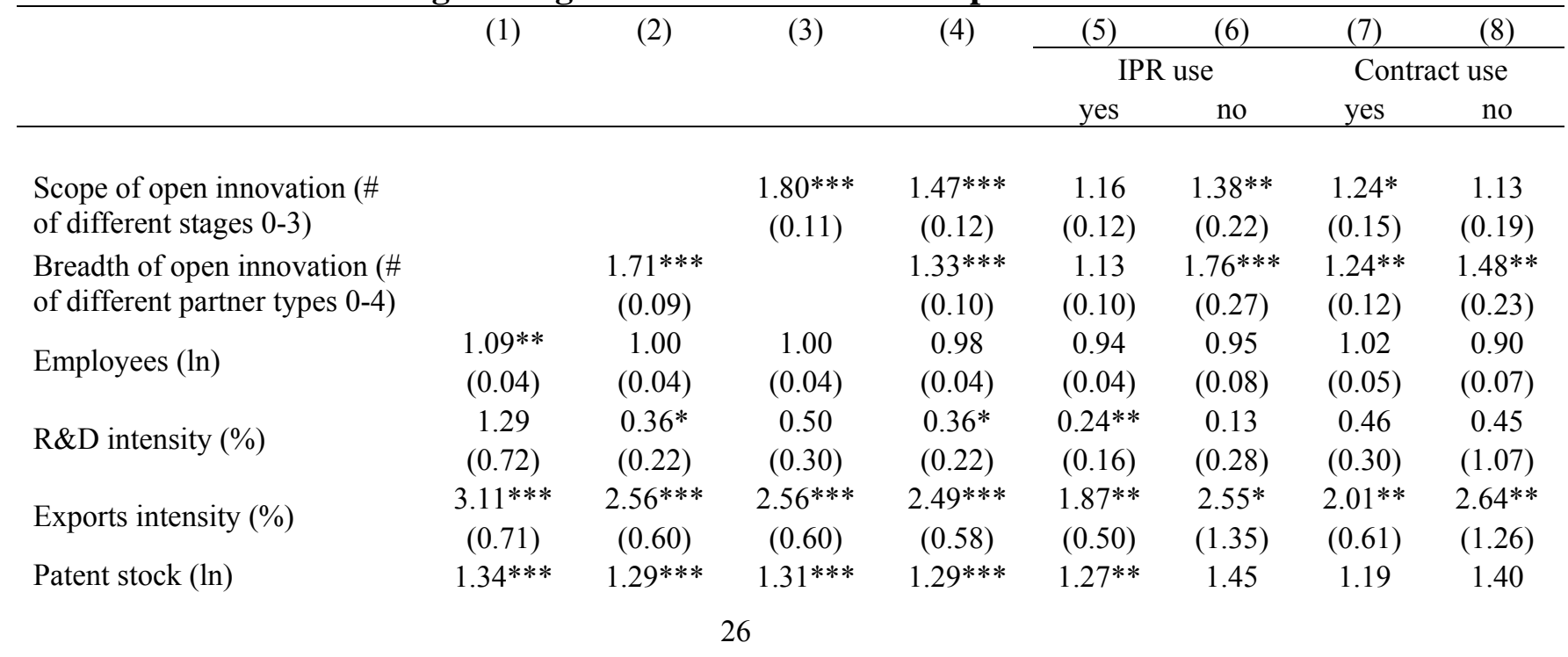




\begin{tabular}{lcccccccc} 
& $(0.13)$ & $(0.13)$ & $(0.13)$ & $(0.13)$ & $(0.12)$ & $(0.63)$ & $(0.14)$ & $(0.31)$ \\
Trademark stock (In) & 0.96 & 0.97 & 0.98 & 0.98 & 0.94 & 0.60 & 1.02 & 0.98 \\
& $(0.12)$ & $(0.13)$ & $(0.13)$ & $(0.13)$ & $(0.12)$ & $(0.50)$ & $(0.18)$ & $(0.22)$ \\
IP value (citations/patent) & 1.02 & 1.03 & 1.02 & 1.02 & 1.01 & 1.20 & 1.06 & 1.03 \\
& $(0.03)$ & $(0.04)$ & $(0.04)$ & $(0.04)$ & $(0.04)$ & $(0.35)$ & $(0.05)$ & $(0.13)$ \\
Legal experience & $1.74 * * *$ & $1.62^{* * *}$ & $1.68^{* * *}$ & $1.63^{* * *}$ & $1.55^{* * *}$ & 1.72 & $1.59^{* * *}$ & $1.73^{* * *}$ \\
& $(0.09)$ & $(0.08)$ & $(0.09)$ & $(0.09)$ & $(0.08)$ & $(0.61)$ & $(0.10)$ & $(0.19)$ \\
Industry controls & Yes & Yes & Yes & Yes & Yes & Yes & Yes & Yes \\
& $0.06^{* * *}$ & $0.04^{* * *}$ & $0.03^{* * *}$ & $0.03^{* * *}$ & $0.19^{* * *}$ & $0.02^{* * *}$ & $0.06^{* * *}$ & $0.06^{* * *}$ \\
Constant & $(0.01)$ & $(0.01)$ & $(0.01)$ & $(0.01)$ & $(0.07)$ & $(0.01)$ & $(0.02)$ & $(0.03)$ \\
& & & & & & & & \\
Observations & 2,797 & 2,797 & 2,797 & 2,797 & 1,182 & 1,533 & 1,179 & 654 \\
Loglikelihood & -1117.20 & -1063.73 & -1059.73 & -1052.69 & -688.63 & -296.21 & -595.62 & -269.69 \\
$\chi^{2}$ & 541.41 & 648.34 & 656.33 & 670.43 & 193.40 & 119.97 & 228.79 & 142.46 \\
$\mathrm{R}^{2}$ & 0.20 & 0.23 & 0.24 & 0.24 & 0.12 & 0.17 & 0.16 & 0.21 \\
$\mathrm{P}$ & 0.00 & 0.00 & 0.00 & 0.00 & 0.00 & 0.00 & 0.00 & 0.00 \\
Wald test statistic $\chi^{2}(1)$ & & & & & $36.07 * *$ & & 15.68 \\
\hline
\end{tabular}

$* * * \mathrm{p}<0.01,{ }^{* *} \mathrm{p}<0.05,{ }^{*} \mathrm{p}<0.1$

\section{References}

Ahmad, A., Bosua, R., and Scheepers, R. (2014) Protecting organizational competitive advantage: A knowledge leakage perspective. Computers \& Security, 42, 27-39.

Alexy, O., Criscuolo, P., and Salter, A.J. (2009) Does IP Strategy Have to Cripple Open Innovation? MIT Sloan Management Review, 51, 1, 71-77.

Alexy, O., George, G., and Salter, A.J. (2013) Cui Bono? The Selective Revealing of Knowledge and Its Implications for Innovative Activity. Academy of Management Review, 38, 2, 270-291.

Allison, P.D. (2002) Missing data. Thousand Oaks, Calif.: Sage Publications.

Anton, J.J. and Yao, D.A. (2004) Little Patents and Big Secrets: Managing Intellectual Property. RAND Journal of Economics, 35, 1, 1-22.

Becerra, M., Lunnan, R., Huemer, L. (2008) Trustworthiness, risk, and the transfer of tacit and explicit knowledge between alliance partners. Journal of Management Studies, 45, 4, 691-713.

Belderbos, R., Carree, M., and Lokshin, B. (2004) Cooperative R\&D and firm performance. Research Policy, 33, 10, 1477-1492.

Berger, F., Blind, K., and Cuntz, A. (2012) Risk factors and mechanisms of technology and insignia copying - A first empirical approach. Research Policy, 41, 2, 376-390.

Bogers, M. (2011) The open innovation paradox: knowledge sharing and protection in R\&D collaborations. European Journal of Innovation Management, 14, 1, 93-117.

Breschi, S., Malerba, F., and Orsenigo, L. (2000) Technological regimes and Schumpeterian patterns of innovation. The Economic Journal, 110, 388-410.

Brusoni, S., Prencipe, A., and Pavitt, K. (2001) Knowledge Specialization, Organizational Coupling, and the Boundaries of the Firm: Why Do Firms Know More Than They Make? Administrative Science Quarterly, 46, 4, 597-621.

Buss, P. and Peukert, C. (2015) R\&D outsourcing and intellectual property infringement. Research Policy, 44, 4, 977-989.

Cassiman, B. and Veugelers, R. (2002) R and D Cooperation and Spillovers: Some Empirical Evidence from Belgium. American Economic Review, 92, 4, 1169-1184.

Ceccagnoli, M. (2009) Appropriability, preemption, and firm performance. Strategic Management Journal, 30, 1, 81-98. 
Chesbrough, H.W. (2003) Open Innovation: The New Imperative for Creating and Profiting from Technology. Boston, MA: Harvard Business Press.

Cohen, W.M. and Levinthal, D.A. (1990) Absorptive capacity: A new perspective on learning and innovation. Administrative Science Quarterly, 35, 1, 128-152.

Czarnitzki, D., Hussinger, K., and Schneider, C. (2015) R\&D Collaboration with Uncertain Intellectual Property Rights. Review of Industrial Organization, 46, 2, 183-204.

Dahlander, L. and Gann, D.M. (2010) How open is innovation? Research Policy, 39, 6, 699-709.

Dyer, J.H. and Singh, H. (1998) The Relational View: Cooperative Strategy and Sources of Interorganizational Competitive Advantage. Academy of Management Review, 23, 4, 660-679.

Easterby-Smith, M., Lyles, M.A., Tsang, E.W.K. (2008) Inter-organizational knowledge transfer: current themes and future prospects. Journal of Management Studies, 45, 4, 677-690.

Evangelista R. and Vezzani, A (2010) The economic impact of technological and organizational innovations. A firm-level analysis. Research Policy, 39, 10, 1253-1263.

Faria, P. de and Sofka, W. (2010) Knowledge protection strategies of multinational firms-A cross-country comparison. Research Policy, 39, 7, 956-968.

Foss, N.J., Husted, K., and Michailova, S. (2010) Governing Knowledge Sharing in Organizations: Levels of Analysis, Governance Mechanisms, and Research Directions. Journal of Management Studies, 47, 3, 455-482.

Frishammar, J., Ericsson, K., and Patel, P. C. (2015) The dark side of knowledge transfer: exploring knowledge leakage in joint R\&D projects. Technovation, 41-42, 75-88.

Gallié, E.-P. and Legros, D. (2012) French firms' strategies for protecting their intellectual property. Research Policy, 41, 4, 780-794.

Gans, J.S. and Stern, S. (2003) The product market and the market for "ideas": commercialization strategies for technology entrepreneurs. Special Issue on Technology Entrepreneurship and Contact Information for corresponding authors, 32, 2, 333-350.

Gassmann, O. and Bader, M.A. (2006) Intellectual Property Management in Inter-firm R\&D Collaborations. Taiwan Academy of Management Journal, 6, 2, 217-236.

Gassmann, O., Enkel, E., and Chesbrough, H.W. (2010) The future of open innovation. $R \& D$ Management, 40, 3, 213-221.

Giarratana, M.S. and Mariani, M. (2014) The relationship between knowledge sourcing and fear of imitation. Strategic Management Journal, 35, 8, 1144-1163.

Grimpe, C. and Kaiser, U. (2010) Balancing Internal and External Knowledge Acquisition: The Gains and Pains from R\&D Outsourcing. Journal of Management Studies, 47, 8, 1483-1509.

Hagedoorn, J. (1993) Understanding the rationale of strategic technology partnering: Interorganizational modes of cooperation and sectoral differences. Strategic Management Journal, 14, 5, 371-385.

Hagedoorn, J. (2002) Inter-firm R\&D partnerships: an overview of major trends and patterns since 1960. Research Policy, 31, 4, 477-492.

Hamel, G. (1991) Competition for competence and interpartner learning within international strategic alliances. Strategic Management Journal, 12, S1, 83-103.

Harhoff, D. and Reitzig, M. (2004) Determinants of opposition against EPO patent grants: the case of pharmaceuticals and biotechnology. International Journal of Industrial Organization, 22, 4, 443-480.

Heiman, B.A. and Nickerson, J.A. (2004) Empirical evidence regarding the tension between knowledge sharing and knowledge expropriation in collaborations. Managerial and Decision Economics, 25, 67, 401-420.

Henkel, J., Schöberl, S., and Alexy, O. (2014) The emergence of openness: How and why firms adopt selective revealing in open innovation. Open Innovation: New Insights and Evidence, 43, 5, 879-890.

Henttonen, K., Hurmelinna-Laukkanen, P., and Ritala, P. (2016) Managing the appropriability of R\&D collaboration. $R \& D$ Management, 46, S1, 145-158. 
Hertzfeld, H.R., Link, A.N., and Vonortas, N.S. (2006) Intellectual property protection mechanisms in research partnerships. Property and the pursuit of knowledge: IPR issues affecting scientific research, 35, 6, 825-838.

Hoecht, A. and Trott, P. (2006) Innovation risks of strategic outsourcing. Technovation, 26, 672681.

Hurmelinna-Laukkanen, P. and Puumalainen, K. (2007) Nature and dynamics of appropriability: strategies for appropriating returns on innovation. R\&D Management, 37, 2, 95-112.

Hurmelinna-Laukkanen, P. and Olander, H. (2014) Coping with rivals' absorptive capacity in innovation activities. Technovation, 34, 3-11.Hussinger, K. (2006) Is silence golden? Patents versus secrecy at the firm level. Economics of Innovation and New Technology, 15, 8, 735752.

Husted, K. and Michailova, S. (2010) Dual Allegiance and Knowledge Sharing in Inter-firm R\&D Collaborations. Organizational Dynamics, 39, 1, 37-47.

James, S. D., M. J. Leiblein, and Lu, S. (2013) How Firms Capture Value From Their Innovations. Journal of Management 39, 5, 1123-1155.

Kaiser, U. (2002) Measuring knowledge spillovers in manufacturing and services: An empirical assessment of alternative approaches. Research Policy, 31, 1, 125-144.

Katila, R. and Ahuja, G. (2002) Something Old, Something New: A Longitudinal Study of Search Behavior and New Product Introduction. Academy of Management Journal, 45, 6, 1183-1194.

Kleinknecht, A. and Reijnen, J.O.N. (1992) Why do firms cooperate on R\&D? An empirical study. Research Policy, 21, 4, 347-360.

Kultti, K., Takalo, T., and Toikka, J. (2007) Secrecy versus patenting. RAND Journal of Economics, 38, 1, 22-42.

Laursen, K. and Salter, A.J. (2006) Open for innovation: the role of openness in explaining innovation performance among U.K. manufacturing firms. Strategic Management Journal, 27, $2,131-150$.

Laursen, K. and Salter, A.J. (2014) The paradox of openness: Appropriability, external search and collaboration. Research Policy, 43, 5, 867-878.

Leiponen, A.E. and Helfat, C.E. (2011) Location, Decentralization, and Knowledge Sources for Innovation. Organization Science, 22, 3, 641-658.

Love, J.H., Roper, S., and Bryson, J.R. (2011) Openness, knowledge, innovation and growth in UK business services. Research Policy, 40, 10, 1438-1452.

Mairesse, J. and Mohnen, P. (2010) Using Innovation Surveys for Econometric Analysis, In Hall, B. H. and Rosenberg, N. In: Handbook of the Economics of Innovation, Vol. 2, Burlington: Academic Press, 1129-1156.

Mansfield, E. (1985) How rapidly does new industrial technology leak out? Journal of Industrial Economics, 34, 2, 217-223.

Manzini, R. and Lazzarotti, V. (2015) Intellectual property protection mechanisms in collaborative new product development. $R \& D$ Management, forthcoming.

Mayer, K.J. and Salomon, R.M. (2006) Capabilities, Contractual Hazards, and Governance: Integrating Resource-Based and Transaction Cost Perspectives. Academy of Management Journal, 49, 5, 942-959.

Miotti, L. and Sachwald, F. (2003) Co-operative R\&D: why and with whom?: An integrated framework of analysis. Research Policy, 32, 8, 1481-1499.

Morasch, K. (1995) Moral hazard and optimal contract form for R\&D cooperation. Journal of Economic Behavior \& Organization, 28, 1, 63-78.

Ocasio, W. (1997) Towards an attention-based view of the firm. Strategic Management Journal, 18, S1, 187-206.

Oxley, J.E. (1997) Appropriability Hazards and Governance in Strategic Alliances: A Transaction Cost Approach. Journal of Law, Economics, and Organization, 13, 2, 387-409. 
Oxley, J.E. (1999) Institutional environment and the mechanisms of governance: the impact of intellectual property protection on the structure of inter-firm alliances. Journal of Economic Behavior \& Organization, 38, 3, 283-309.

Oxley, J.E. and Sampson, R.C. (2004) The scope and governance of international R\&D alliances. Strategic Management Journal, 25, 89, 723-749.

Pisano, G.P. and Teece, D.J. (2007) How to Capture Value from Innovation: Shaping Intellectual Property and Industry Architecture. California Management Review, 50, 1, 278-296.

Poppo, L. and Zenger, T. (2002) Do formal contracts and relational governance function as substitutes or complements? Strategic Management Journal, 23, 8, 707-725.

Ritala, P. and Hurmelinna-Laukkanen, P. (2009) What's in it for me? Creating and appropriating value in innovation-related coopetition. Technovation, 29, 12, 819-828.

Ritala, P., Olander, H., Michailova, S., and Husted, K. (2015) Knowledge sharing, knowledge leaking and relative innovation performance: An empirical study. Technovation, 35, 22-31.

Roper, S., Du, J., and Love, J.H. (2008) Modelling the innovation value chain. Research Policy, 37, 6-7, 961-977.

Salerno, M.S., Gomes, L.A., Silva, D., Bagno, R.B., and Freitas, S. (2015) Innovation processes: Which process for which project? Technovation, 35, 59-70.

Sampson, R.C. (2004) The Cost of Misaligned Governance in R\&D Alliances. Journal of Law, Economics, and Organization, 20, 2, 484-526.

Saren, M.A. (1984) A classification and review of models of the intra-firm innovation process. $R \& D$ Management, 14, 1, 11-24.

Schubert, T. (2015) Infringement of intellectual property in innovation partnerships. $R \& D$ Management, forthcoming.

Slowinski, G., Hummel, E., and Kumpf, R.J. (2006) Protecting Know-How And Trade Secrets In Collaborative R\&D Relationships. Research-Technology Management, 49, 4, 30-38.

Somaya, D., Kim, Y., and Vonortas, N.S. (2011) Exclusivity in licensing alliances: using hostages to support technology commercialization. Strategic Management Journal, 32, 2, 159 186.

Teece, D.J. (1986) Profiting from technological innovation: Implications for integration, collaboration, licensing and public policy. Research Policy, 15, 6, 285-305.

Tether, B.S. (2002) Who co-operates for innovation, and why: An empirical analysis. Research Policy, 31, 6, 947-967.

Trott, P. (2008) Innovation management and new product development, 4th edn. Harlow, England, New York: Prentice Hall.

Tsai, W. (2001) Knowledge transfer in intraorganizational networks: Effects of network position and absorptive capacity on business unit innovation and performance. Academy of Management Journal, 44, 5, 996-1004.

Utterback, J.M. (1971) The Process of Technological Innovation Within the Firm. Academy of Management Journal, 14, 1, 75-88.

Utterback, J.M. (1974) Innovation in industry and the diffusion of technology. Science, 183, $4125,620-626$. 